\title{
Impact of High Commitment Human Resource Management Practices on Performance in Chinese SME
}

\author{
Chao Ling $^{1} \&$ Fuangfa Amponstira ${ }^{2}$ \\ ${ }^{1}$ Ph.D. Candidate, Management, School of Management, Shinawatra University, Thailand \\ ${ }^{2}$ Management, School of Management, Shinawatra University, Thailand \\ Correspondence: Chao Ling, Management, School of Management, Shinawatra University, Thailand.
}

Received: September 14, 2021

Accepted: October 4, 2021

Online Published: October 7, 2021

doi:10.5539/ibr.v14n11p24

URL: https://doi.org/10.5539/ibr.v14n11p24

\begin{abstract}
High Commitment Human Resource Management is a commonly used human resource management method. Scholars' research mostly focuses on its impact on organizational performance, ignoring the importance of individual employees' behavior in modern enterprises. Based on AMO theory. This paper is taking China's small and medium-sized enterprises as the research object, to discuss the mechanism of the High Commitment Human Resource Management Practices on Performance perceived by employees in the organization. Data from 420 empirical Guangzhou textile companies show that high-commitment human resource management can significantly improve performance, and the ability system, motivation system, and opportunity system can all promote performance.
\end{abstract}

Keywords: high commitment human resource management practices, performance, SME

\section{Introduction}

The era of knowledge economy has arrived. In the era of information, networking, knowledge commodification, traditional production factors such as land, capital, and labor play less and less role in corporate competition. Organizational links such as corporate management systems, operating procedures, core values, employee behaviors, and competence have become key resource for improving the competitiveness of enterprises. The implementation of the human resource management system can change the attitude of employees (Wang Decai \& Zhao Shuming, 2013), guide their behavior, and effective human resource management practices can guide employees to act in line with organizational goals, as well as improving the competitiveness of the company. Moreover, only a company with a comprehensive and comprehensive human resource management system can improve its sustainable competitiveness. Human resource management practice as a management tool, only a human resource management system that has both internal and external compatibility can play a role in corporate management. Teece, Pisano \& Shuer (1998) constructed the theory of dynamic capabilities. By integrating the enterprise model and resource-based view in evolutionary economics, it also positioned the acquisition of competitive advantage in the endogenous creation of enterprise knowledge, resources and capabilities.

The sustainable competitive advantage of an enterprise depends on whether it has the knowledge and skills that affect the core competence of the enterprise. Human capital has been increasingly regarded as the core factor of corporate growth. High-commitment human resource management aims to emphasize the improvement of employees' skills, enhance work motivation and provide opportunities to participate in decision-making to improve organizational performance. It is also known as a high-performance work system. As a human resource management method implemented within an enterprise, it is bound to be affected by exogenous factors such as political environment, economic background, cultural environment, labor market, etc. It also has a certain relationship with corporate strategy, scale, and organizational structure. The research in this paper focuses on the individual level of employees, exploring the impact of high-commitment human resource management practices on employees performance.

As the most effective human resource management model at present, the high-commitment human resource management system can enable the company and its employees to establish a mutual commitment relationship, improve employee satisfaction, and increase employee loyalty, so that employees are willing to stay in the company and serve the company. However, knowledge replaces materials and becomes the key to corporate 
competition, employees' self-awareness increases, and employee recognition is no longer a guarantee for staying in the company and dedicating themselves. Employees are more pursuing the realization of self-worth and the balance between pay and return. Companies need to implement high-commitment human resource management, adopt effective management measures in recruitment and selection, motivation and training, and form organizational commitments with employees, so that employees are motivated and capable to complete their work and achieve high-performance output.

\section{Theory and Hypotheses}

\subsection{AMO Theory}

AMO theory(Ability - Motivation - Opportunity), is one of the important theories explaining the impact of human resource management system on employee behavior, and one of the most important theoretical frameworks of "behavior perspective". The theory originated from career development. The initial view was that employees in an organization need to have the ability to match their work and the motivation to work hard. In addition, employees also need to have the opportunity to continue learning and development in the organization. Only when these conditions are met, employees can succeed in their careers. From the "behavior perspective" research, it is found that human resource management practices play a role in corporate management, mainly by improving incentive conditions or increasing human capital reserves. An effective human resource management system is to improve the personal ability of employees, give opportunities to participate, guide work motivation, and prompt them to show the behavior expected by the organization.

In the early research on the application of the AMO model (Ability-Motivation-Opportunity), in the field of human resource management, MacDuffie proposed that in a specific work system, employees have a certain degree of work ability and work motivation at the same time. This system can work when it gives employees the opportunity to participate. Huselid proposed that the best human resource management mode of an enterprise should focus on improving work ability and increasing work motivation, and made a preliminary division of best human resource management practices. This model has been recognized by many scholars, who believe that an effective human resource management system should target technology, motivation, and authorization. More scholars pointed out that the three elements of ability, motivation and opportunity model are interrelated. When employees have certain ability and can feel the benefits of successful feedback, they will have the motivation to perform more responsibilities and undertake more tasks (Ehrnrooth , M., \& Bj Rkman, I., 2012), which provides effective management suggestions for companies to improve employee performance, and provides a reference for the preliminary design of human resource management systems.

With the continuous development of human resource management, scholars have carried out research on the abilities, motivations and opportunities of human resource management systems, and put forward the AMO theory. Human resource management practices can be divided into three basic practice types: human resource practices to improve employee abilities, human resource practices to promote motivation, and human resource practices to increase employee opportunities, which are conducive to the improvement of organizational performance (Jiang et al., 2012) . Based on the AMO model, Jiang et al. (2012) conducted analysis of the relationship between the human resource system and the organization results, and found that the three dimensions of the human resource management system: the ability system, the opportunity system and the motivation system, all of which can affect the organization's Financial results, human cost and employee behavior positively. Among them, the ability system practice has a particularly significant role in promoting human capital. Therefore, this paper also uses ability system, opportunity system and motivation system to represent the high-commitment human resource management system.

\subsection{High Commitment Human Resource Management Practices}

As HCHRMP are also referred to as high-commitment HR practices, high-opportunity in HR practices, or best HR practices (Kwon, 2010). Research on High Commitment Human Resource Management (HCHRMP) can be traced back to the late 1980s, when faced with a complex and volatile market environment, research scholars in strategic human resource management suggested that enterprises should Create a human resource management system designed to enhance the competitive advantage of the organization. Although the names of different scholars are different, these systems are designed to improve the attitude and behavior of employees and their job skills, motivations, and opportunities for opportunity. (Wood, 2012)

The definition of HCHRMP can be based on both broad sense and chivalry (Zhang Zhengtang and Li Rui, 2015). The broad definition emphasizes the use of various human resources means to improve organizational performance. Scholars believe that in order to achieve better performance, employees need to have three elements: higher job skills, motivation to work hard (Motivation), and opportunity to participate in work 
decisions (Opportunity), which is famous as "AMO" model (Appelbaum, 2006). Many scholars use the AMO model to define the content of a high-commitment work system (Edwards \& Wright, 2001; Combs, 2006; Lin Sun., 2007). They all consider HCHRMP as a working system through some intermediary variables, such as work. Attitudes, skills, knowledge, etc., to change the behavior of employees, thereby enhancing the core competitive advantage of the organization. Heffernan (2016) considered the three dimensions proposed in the "AMO" model: higher job skills, motivation to complete work, and opportunity to participate in work decisions (Opportunity) for the high committed human resource management.

\subsection{Hypotheses}

Based on the AMO model, this paper uses the ability system, opportunity system and motivation system to measure high-commitment human resource management.The ability system of high-commitment human resource management includes a series of measures that are conducive to improving employee skills, such as strict recruitment and internal training. Strict recruitment procedures aim to select employees who can complete work tasks and are compatible with the development of the organization, and help companies select talents who have the ability to work and learn, but also quickly integrate into the organizational culture and working environment, so that employees recognize the company and are willing to work hard. Work. Extensive training can give employees new roles and responsibilities, which not only improves their skills and promotion possibilities, but also reserves talents for the long-term development of the organization. Chinese scholars $\mathrm{Xu}$ Guohua and Yang Dongtao (2005) also found through a survey of manufacturing companies that growth and training can increase the sales growth rate of companies. According to the social exchange theory, if employees perceive the goodwill of the organization, they will reward the organization with the behavior expected by the organization. When the organization pays for employee training, it will prompt employees to repay work-related behaviors that satisfy the organization (Zhang, 2017). On one hand, the training of employee skills is the improvement of personal abilities, and on the other hand, it pays attention to the long-term development of employees, so that employees have the capital and motivation to invest in their work and improve their work performance. In addition, the improvement of employee skills has also improved the ability of employees to complete work tasks, and also enabled employees to help other members. This paper proposes hypotheses below on the base of the above statements:

H1: Ability system is positively correlated with employee performance.

The incentive system of high-commitment human resource management includes management methods such as stable performance evaluation, fair remuneration within the organization and high salaries. Such an organization can fairly and justly repay employees for their contributions, recognize their contributions and treat valuable employees fairly. The behavior of employees in repaying the organization is the dual result of the principle of reciprocity and rational cognition, and it is also affected by the internal motivation of employees. According to the behaviorist principles of social exchange theory, human beings are in a network of relationships, and their behaviors always pursue the maximization of benefits and the minimization of costs. Only when positive reinforcement or the cost is minimal, will people repeat certain behaviors. Therefore, when employees perceive that the company pays attention to performance evaluation, high salary and respect for the hard work process, they will reward the organization with excellent team performance and high personal contribution, which can continue to bring higher benefits to employees, high returns, The evaluation method of team performance gives employees the motivation to help others and work hard, and the employee's contribution will continue to receive further awards from the company, and the employee' s motivation for work will increase.This paper proposes hypotheses below on the base of the above statements:

$\mathrm{H} 2$ : Motivation system is positively correlated with employee performance.

Opportunity in management reflects the organization's respect and trust for employees, and expresses the organization's expectations for employees to participate in decision-making. According to the theory of social exchange, when employees perceive friendly information such as help and support from the organization, they will feel the need to give back to the organization (Mohrman, 1995). Only when employees perceive organizational values and organizational fairness, they will reward the organization in a more positive way (Bartol \& Srivastava, 2002). The opportunity system of high-commitment human resource management emphasizes that employees within the organization are as equal as possible and employee opportunity Human resource management methods such as management decision-making and emphasizing employee suggestions, these management measures are conducive to employees to increase their sense of organizational fairness, recognize corporate culture, improve employee enthusiasm for work, and guide employees to return to the organization to behave more positively. Therefore,this paper proposes hypotheses below on the base of the above 
statements:

H3: Opportunity system is positively correlated with employee performance.

\section{Method}

\subsection{Data Collection}

In this paper, through the secretary of the Guangdong Textile Association, the researchers distributed questionnaires according to the corresponding proportions, and distributed 64 copies to the primary management representatives in the industry associations, 316 copies to the representatives of the production technicians, and 205 copies to the sales service personnel representatives. Through them, the questionnaires are sent to the sample objects on the same-group staff list by simple sampling.( random number table) A total of 585 questionnaires were distributed, and 471 samples were finally collected. After screening, 420 valid samples were obtained.

\subsection{Variables Measurement}

The specific content of the high-commitment human resource management practice has not yet reached a unified opinion in academia. Jeffrey (1996) put forward 16 universal human resource practices that can enhance the competitive advantage of enterprises, which were then integrated into 7 practices of "work safety, strict recruitment, extensive training, information sharing, self-management team, performance compensation and fairness". It is generally recognized as the best model of human resource practice. Xiao \& Bjorkman (2006) developed a high-commitment human resource management scale based on the Chinese context based on the research of previous scholars by investigating employees in China' s information technology industry, with a total of 15 items, and pointed out that high-commitment human resources Specific practical content of management. This research uses the Xiao \& Bjorkman scale, which includes 14 items such as "the company has strict selection procedures when recruiting employees", "the company provides me with high remuneration", and "the company emphasizes achieving long-term goals".

The measurement of performance is generally valued by scholars. Borman (1993) first proposed a two-dimensional structural model for task performance and relationship performance. Since then, Hesketh has added adaptive performance on this basis and passed empirical tests to design a three-dimensional structural model. Since then, Chinese scholar Wen (2019) designed a four-dimensional structural model of task performance, interpersonal performance, adaptation performance, and effort performance. The scale designed has passed verification in the Chinese context. This paper adopts the structure model of Borman \& Motowidlo. The scale was originally derived from Campell's questionnaire. It includes 10 items such as"I have a clear plan for the work I am responsible for and abide by the company's discipline" and "I take the initiative to undertake, deal with and solve problems.

\section{Analyses and Results}

\subsection{Reliability and Validity Analysis}

Reliability analysis is to test the consistency and stability of the scale and its variables, which can better ensuring the reliability of the scale used, so that the collected data can meet the needs of the research. In empirical research, scholars generally use Cronbach's a coefficient to measure reliability. Among them, when Cronbach's a is above 0.5 , it means that the reliability of this item is acceptable, greater than 0.7 means a high level of reliability, and greater than 0.8 means very high. In this study, the SPSS 21.0 software was used to analyze the items of each scale, and the reliability analysis results are shown in Table 1.

It can be seen from the above table that the Cronbach $\alpha$ values of the independent variables are 0.776, 0.862 and 0.832 and the overall Cronbach $\alpha$ value of the independent variables is 0.909 , the dependent variable Cronbach $\alpha$ values is 0.813 , indicating that the reliability of the research data is high, and all the items should be retained for further analysis. The CITC values corresponding to the analysis items are all higher than 0.7 , thus indicating that there is a good correlation between the analysis items, and also indicating that the reliability level is good.

In this paper, confirmatory factor analysis is carried out through AMOS 24.0, and the validity of each scale is verified through the judgment of important indicators. The general judgment standard is $\chi 2 / \mathrm{df}<3$, RMSEA $<0.05$, $\mathrm{CFI}>0.9$, GFI $>0.9$, IFI>0.9. By running AMOS24 and analyzing the three-factor confirmatory factor of high-commitment human resource management, $\chi 2 / \mathrm{df}$ is $4.5, \mathrm{GFI}=0.92, \mathrm{CFI}=0.91$, IFI $=0.91$, all exceeding the ideal level of 0.9 , RMSEA $=0.042$, indicating that the three-factor model of high-commitment human resource management has a good fit. From the two-factor analysis indicators of the performance scale, $\chi 2 / \mathrm{df}$ is $4.75, \mathrm{GFI}=0.96, \mathrm{CFI}=0.97, \mathrm{IFI}=0.98$, all exceeding the ideal level of $0.9, \mathrm{RMSEA}=0.035$, indicating that the two-factor model of the performance scale Good fit. Therefore, this questionnaire has good validity. 
Table 1. Reliability Analysis

\begin{tabular}{|c|c|c|c|}
\hline Variable & Items & CITC & Cronbach $\alpha$ \\
\hline \multirow{5}{*}{ Ability system } & Q1 & 0.776 & \multirow{5}{*}{0.776} \\
\hline & Q2 & 0.863 & \\
\hline & Q3 & 0.785 & \\
\hline & Q4 & 0.810 & \\
\hline & Q5 & 0.778 & \\
\hline \multirow{5}{*}{ Motivation system } & Q6 & 0.804 & \multirow{5}{*}{0.862} \\
\hline & Q7 & 0.835 & \\
\hline & Q8 & 0.777 & \\
\hline & Q9 & 0.827 & \\
\hline & Q10 & 0.805 & \\
\hline \multirow{5}{*}{ Opportunity system } & Q11 & 0.828 & \multirow{5}{*}{0.832} \\
\hline & Q12 & 0.835 & \\
\hline & Q13 & 0.819 & \\
\hline & Q14 & 0.805 & \\
\hline & Q15 & 0.811 & \\
\hline \multirow{10}{*}{ Performance } & Q16 & 0.753 & \multirow{10}{*}{0.813} \\
\hline & Q17 & 0.845 & \\
\hline & Q18 & 0.781 & \\
\hline & Q19 & 0.844 & \\
\hline & Q20 & 0.788 & \\
\hline & $\mathrm{Q} 21$ & 0.843 & \\
\hline & Q22 & 0.855 & \\
\hline & Q23 & 0.787 & \\
\hline & Q24 & 0.856 & \\
\hline & $\mathrm{Q} 25$ & 0.834 & \\
\hline
\end{tabular}

\subsection{Descriptive Statistics and Correlation Analysis}

Table 2 shows among the 420 valid questionnaires, there were 235 males, accounting for $55.96 \%$, and 185 females, accounting for $44.04 \%$. The age is concentrated in $20-50$ years old, accounting for $70 \% .285$ people were employed as common staff, accounting for $67.85 \%$ of the total sample; 135 were employed as primary team leader, accounting for $32.15 \%$ of the total sample. Most enterprise hire less than 300 employees, which accounting for $76 \%$.

Correlation analysis can point out the degree of close connection between the two variables. This study uses the Person correlation coefficient method to analyze the correlation between high-commitment human resource management and performance and its various aspects. The analysis results are shown in Table 2.There is a significant correlation between the four main variables of Ability system, Motivation system, Opportunity system, Performance. There is a significant impact from Ability system $(r=0.524, \mathrm{p}<0.01)$, Motivation system $(\mathrm{r}=0.502, \mathrm{p}<0.01)$, Opportunity system $(\mathrm{r}=0.564, \mathrm{p}<0.01)$ on Performance.Assume that $\mathrm{H} 1, \mathrm{H} 2$, and $\mathrm{H} 3$ are initially verified. The test of the correlation coefficient only reflects the correlation between the two, and the degree of influence needs to be verified in the next step.

Table 2. Correlation analysis

\begin{tabular}{cccccccccc}
\hline & 1 & 2 & 3 & 4 & 5 & 6 & 7 & 8 & 9 \\
\hline 1.Gender & 1 & & & & & & & & \\
2.Age & .043 & 1 & & & & & & \\
3.Degree & .056 & & 1 & & & & & \\
4.Job level & $.175^{*}$ & .011 & $.207^{* *}$ & 1 & & & & \\
5.Enterprise scale & .043 & $.106^{*}$ & $.143^{* *}$ & $.230^{* *}$ & 1 & & & \\
6.Ability system & .026 & .071 & $.314^{* *}$ & $.148^{* *}$ & $.763^{* *}$ & 1 & & & \\
7.Motivation system & $.196^{*}$ & .011 & $.207^{* *}$ & $.095^{* *}$ & $.722^{* *}$ & $.832^{* *}$ & 1 & & \\
8.Opportunity system & $.183^{*}$ & $.106^{*}$ & $.146^{* *}$ & $.691^{* *}$ & $.455^{* *}$ & $.415^{* *}$ & $.448^{* *}$ & 1 & \\
9.Performance & $.257^{*}$ & .071 & $.219^{* *}$ & $.230^{* *}$ & $.466^{* *}$ & $.524^{* *}$ & $.502^{* *}$ & $.564^{* *}$ & 1 \\
\hline
\end{tabular}

Note: ** Correlation is significant at the 0.01 level (2-tailed).

* Correlation is significant at the 0.05 level (2-tailed).

\subsection{Hypothesis Test}

Table 3 summarizes the regression analysis results of high-commitment human resource management and performance. Among them, Model 1 shows the impact of the control variable on the dependent variable. Model 2 
shows the hierarchical regression results of the ability system and performance. $\mathrm{R} 2$ is 0.369 and $\mathrm{F}$ value is 12.699. The analysis results all reach a significant level of 0.001 , indicating that the ability system's model fit to performance is acceptable and the regression effect is good. The $\mathrm{P}$ value is 0.398 (sig. <0.01), which means that the competency system can significantly promote task performance, and every $1 \%$ increase in the competence system can improve performance by $39.8 \%$. Assuming $\mathrm{H} 1$ is supported, further verification is passed. Model 3 shows the results of the hierarchical regression of the relationship between the incentive system and performance. $\mathrm{R} 2$ is 0.394 and $\mathrm{F}$ value is 13.327 . The analysis results all reach a significant level of 0.001 , indicating that the incentive system has a good performance regression effect, with a P value of 0.304 (sig. $<0.01$ ), which means that the incentive system can significantly promote performance, assuming $\mathrm{H} 2$ is supported. Model 4 shows the regression results of the relationship between opportunity system and performance, $\mathrm{R} 2$ is $0.554, \mathrm{~F}$ value is 24.156 , and the analysis results reach a significant level at 0.001 , indicating that the incentive system has a good performance regression effect, with a $\mathrm{P}$ value of 0.326 (sig. $<0.01$ ), which means that the incentive system can significantly promote performance, assuming $\mathrm{H} 3$ is supported.

Table 3. Regression Analysis of HCHRMP and Performance

\begin{tabular}{ccccc}
\hline Variable & Model 1 & Performance & Model 3 & Model 4 \\
\hline Gender & 0.054 & 0.031 & 0.053 & 0.087 \\
Age & -0.067 & $0.109 * *$ & 0.052 & 0.048 \\
Degree & 0.066 & $0.109 *$ & 0.064 & 0.063 \\
Job level & 0.034 & 0.032 & $0.066^{*}$ & 0.056 \\
Enterprise scale & $0.129^{* *}$ & 0.108 & 0.010 & 0.005 \\
Ability system & & $0.398 * *$ & $0.234^{* *}$ & $0.249^{* *}$ \\
Motivation system & & & $0.304^{* * *}$ & $0.258^{* * *}$ \\
Opportunity system & & & $0.326^{* * *}$ \\
$\mathrm{R}^{2}$ & 0.346 & 0.369 & 0.394 & 0.554 \\
$\triangle \mathrm{R}^{2}$ & 0.365 & 0.783 & 0.589 & 0.643 \\
$\mathrm{~F}$ & $11.865^{* * *}$ & $12.699^{* * *}$ & $13.327^{* * *}$ & $24.156^{* * *}$ \\
\hline
\end{tabular}

Note: $* \mathrm{p}<0.05, * * \mathrm{p}<0.01, * * * \mathrm{p}<0.001$

\section{Conclusion}

\subsection{Major Findings}

Based on AMO theory and social exchange theory, this paper explores the mechanism of high-commitment human resource management under employee perception on job performance. Through data analysis, it is concluded that Ability system is positively correlated with performance; Motivation system is positively correlated with performance; Opportunity system is positively correlated with performance.High-commitment human resource management has a positive correlation with performance. High-commitment human resource management can significantly improve performance. The higher the level of high-commitment human resource management we conduct, the higher the performance of employees we get. Ability system, motivation system, and opportunity system can all promote performance improvement. The skill level and skill level of employees are the most important factors in completing work tasks, which directly determine the quality of the completed work. Humans are profit-seeking animals, and certain behaviors occur only when they gain benefits. Human resource management methods such as team performance appraisal, high salaries, and future skill acquisition can encourage employees to challenge themselves, help others, and value team interests.

\subsection{Contribution}

The high-commitment human resource management system is a human resource management tool implemented by the organization to improve performance. The results of its implementation are directly reflected in performance and organizational performance. The organization should have a correct understanding of the high-commitment human resource management system. It is not a method that can produce results. It requires employees to evaluate whether they feel that the high-commitment human resource management system is implemented in personal work and in the organization, and whether it is good for themselves The performance generated motivation. The enterprise needs to establish a transparent information exchange platform within the enterprise, so that every member can understand the company' s recruitment requirements, training targets, performance appraisal methods, salary basis, and human resource management methods such as corporate trends 
and cultural equality. Employees truly feel the implementation of the organization's high-commitment human resource management, so that employees can establish a commitment with the organization and strive to improve personal performance.

Enterprises must build a distinctive high-commitment human resource management system. Due to differences in the competitive environment, work nature, corporate culture, etc., organizations need to develop a high-commitment human resource management system that can solve practical problems and improve performance based on the actual situation of the company and the work performance of employees. It is necessary to realize that under the situation of increasingly fierce competition among enterprises, the measurement of performance is not limited to the completion of their own work. Enterprises need outstanding talents who have a big picture and take the initiative to challenge difficult tasks. When an enterprise finds that its work performance is poor, it should break down and refine its performance. Don't blindly build a high-commitment human resource management system. Only in-depth texture we can build an effective high-commitment human resource management system and truly improve work performance.

Expanding research on the role of high-commitment human resource management suggests that the mechanism of high-commitment human resource resources on job performance is more clearly. In addition, this paper constructs a relationship model of high-commitment human resource management, knowledge sharing, and performance. To a certain extent, it has enriched the research of strategic human resource management theory and expanded the research channels of high-commitment human resource management.

\section{Limitations}

This study explores the impact of HCHRMP on performance. It has certain contributions in both theory and practice. However, due to various resources and conditions, there are still some defects. Future research can be carried out from the following aspects.

1) Measurements of all variables in this study are based on other people's scales. Although various tests have been carried out and meet the requirements, there is no way to avoid a certain degree of influence.

2)The role of HCHRMP may be affected by other scenarios and individual factors, such as team atmosphere, leadership type and individual characteristics, but this study has not been discussed. Therefore, future research can further consider team safety atmosphere, supportive leadership and The influence of factors such as individual values on the effect of HCHRMP. Future research can consider the effects of certain mediator variables or regulatory variables.

3)This paper only uses the sample of small and medium-sized private textile enterprises in Guangzhou, which has certain limitations in industry and geography. In the future, you can try to do more research in areas and geographies.

\section{References}

Allworth, E. (1997). Adaptive performance: updating the criterion to cope with change.

Bartol, K. M., \& Srivastava, A. (2002). Encouraging knowledge sharing: the role of organizational reward systems. Journal of Leadership \& Organizational Studies, 9(1), 64-76. https://doi.org/10.1177/107179190200900105

Borman, W. C. (1993). Expanding the Criterion Domain to Include Elements of Contextual Performance.

Ehrnrooth, M., \& Bj?Rkman, I. (2012). An integrative hrm process theorization: beyond signalling effects and mutual gains. Journal of Management Studies, 49(6), 1109-1135. https://doi.org/10.1111/j.1467-6486.2012.01055.x

Jeffrey, P. (1996). Competitive advantage through people unleashing the power of the work force, harvard business school press, boston. Journal of Organizational Behavior, 15(6).

Jiang, K., Lepak, D. P., Hu, J., \& Baer, J. C. (2012). How does human resource management influence organizational outcomes? a meta-analytic investigation of mediating mechanisms. Academy of Management Journal, 55(6), 1264-1294. https://doi.org/10.5465/amj.2011.0088

Jiang, K., Lepak, D. P., Han, K., Ying, H., Kim, A., \& Winkler, A. L. (2012). Clarifying the construct of human resource systems: relating human resource management to employee performance. Human Resource Management Review, 22(2), 73-85. https://doi.org/10.1016/j.hrmr.2011.11.005

Mohrman, S. A., Cohen, S. G., \& Jr, A. (1995). Designing team-based organizations: new forms for knowledge work. The Jossey-Bass management series, 7(2), 100.

Wang, D. C., \& Zhao, S. M. (2013). Research on the relationship between human resource management practices 
and employee attitudes: Based on a questionnaire survey of 192 private small and medium high-tech companies in the Pearl River Delta. Business Economics and Management.

Xiao, Z., \& Bjorkman, I. (2006). High commitment work systems in Chinese organizations: a preliminary measure. Management and Organization Review, 2(3), 403-422. https://doi.org/10.1111/j.1740-8784.2006.00049.x

Xu, G. H., \& Yang, D. T. (2005). Supporting human resource practice, flexible strategy and company performance in manufacturing companies. Management World, 000(005), 111-116,169.

Zhang, Y., \& Hou, L. Y. (2017). Research on the Influence Mechanism of High-Performance Work System on Employee Engagement: The Moderated Mediation Effect. Industrial Technology Economy, 36(004), 88-97.

\section{Copyrights}

Copyright for this article is retained by the author(s), with first publication rights granted to the journal.

This is an open-access article distributed under the terms and conditions of the Creative Commons Attribution license (http://creativecommons.org/licenses/by/4.0/). 